\title{
Detection of a New Variant in Outbreak of Bovine Ephemeral Fever in Turkey, 2020
}

\begin{abstract}
Background: In this study, partial nucleotide sequence analysis of the $G$ gene was performed for the molecular characterization of the virus that caused the bovine ephemeral fever virus (BEFV) epidemic in Turkey in 2020. Phylogenetic analysis of these nucleotide sequences was performed with the virus nucleotide sequences of the epidemics seen in 2008 and 2012. These sequences were announced in GenBank. Phylogenetic analysis of these nucleotide sequences was performed with the virus nucleotide sequences of the epidemics seen in 2008 and 2012.

Methods: The study was conducted in dairy cattle holdings located in Diyarbakır Sur, Çınar and Dicle regions in South-eastern Turkey in August-November 2020. The number of animals in the holdings consisted of $750(n=750), 150(n=150)$ and 200 ( $n=200)$ cattle, respectively.

Result: Severe respiratory symptoms and high mortality in the affected animals were notable symptoms. As a result of the phylogenetic analysis, it was determined that the virus that caused the epidemic in Turkey in 2020 was formed by a new variant in the Turkey-2 group, which was similar to the Indian isolates, unlike the Turkey-1 group, which was close to the Middle East variants in 2008 and 2012 isolates.

Key words: Bovine ephemeral fever virus, G gene, Molecular characterization.
\end{abstract}

\section{INTRODUCTION}

Bovine ephemeral fever virus (BEFV) is an arbovirus in the Rhabdoviridae family. It is from the Ephemerovirus genus. The virus locally causes three-day sickness, bovine influenza and infections with the fever called bovine enzootic fever in cattle and water buffalo (Walker and Klement, 2015). The genome is comprised of five structural proteins, namely the nucleoprotein $(\mathrm{N})$, surface glycoprotein $(\mathrm{G})$, RNA polymerase dependent large RNA (L), polymerase associated protein $(P)$ and matrix protein $(M)$. BEFV G protein is in charge of being taken in the target cell. Moreover, it plays a role in protecting virus neutralization with its four different antigenic structures called G1, G2, G3 and G4 (Walker et al., 1991). BEFV can cause fever, nasal discharge, labored breathing, lethargy, shivering, inability to rise and sometimes death (Zaher and Ahmed, 2011). The disease is endemic in tropical and subtropical regions, including Africa, Australia, Kenya, Saudi Arabia, the Middle East, Asia and Turkey (Thabet et al., 2011). Morbidity in endemics is generally between $25 \%-45 \%$, but it can reach $100 \%$ if the population is highly sensitive or the infecting strain is virulent (Radostits et al., 2006). Low mortality, lower milk production and increased treatment costs might lead to financial loss (Thabet et al., 2011). Infection with different variant strains can increase mortality (Radostits et al., 2006). In the BEFV endemic in 2012, the disease prevalence was about $60 \%-80 \%$ in the Çukurova region, while the reported mortality was around $15 \%-20 \%$ (Tonbak et al., 2013).). The virus is spread by being carried by host Culicoides spp. and Mosquitoes with hot winds (Lee, 2019; Pyasi et al., 2020). Since its first introduction in Turkey (Girgin et al., 1986), BEFV was reported in 1999, 2003, 2008,
Department of Microbiology, Faculty of Veterinary, Dicle University, Diyarbakır, Turkey.

Corresponding Author: Neval Berrin Arserim, Department of Microbiology, Faculty of Veterinary, Dicle University, Diyarbakır, Turkey. Email: nevalb@dicle.edu.tr

How to cite this article: Arserim, N.B., Gürçay, M., Sait, A. and Türkdoğan, M. (2022). Detection of a New Variant in Outbreak of Bovine Ephemeral Fever in Turkey, 2020. Indian Journal of Animal Research. DOI: 10.18805/IJAR.BF-1438.

Submitted: 15-09-2021 Accepted: 06-12-2021 Online: 16-01-2022

2012 and 2020 (Alkan et al., 2017; Aziz et al., 2012; Karayel et al., 2021; Oguzoğlu et al., 2015; Tonbak et al., 2013).

The purpose of this study is to make sequence analysis of the $\mathrm{G}$ gene of the virus that caused the BEFV endemic in Turkey in 2020, publish this sequence analysis in GenBank, determine its filiation by comparing these sequences with the virus that caused previous endemics through phylogenetic analyses and demonstrate if there is any difference in the variants of this virus and the one that caused previous endemics.

\section{MATERIALS AND METHODS}

\section{Background and cases of the BEFV 2020 epidemic}

In August 2020, the clinical symptoms of the disease were observed in a few dairy farms in Diyarbakır and its vicinity. There was a herd of 750 cattles settled in the district of Sur. All animals were clinically examined. 300 of the animals in the herd (morbidity $30 \%$ ) were infected and 95 of the infected animals (aged 1 to 4 ) were dead. No clinical symptoms were 
observed in younger animals (about six months). Clinical examinations were made for 150 cattle in a cattle facility in the district of Çınar and 200 cattle in a cattle facility in the district of Dicle and animals affected by the disease in the stated morbidity and mortality rates were identified in Sur. Mosquito traps were placed in wet and damp areas in different areas inside and outside the cattle facilities. After keeping the traps for one week, trapped mosquitos were sampled for a laboratory examination. Defibrinated blood was taken in the fever period from the animals with fever symptoms $\left(41-42^{\circ} \mathrm{C}\right)$, nasal and ocular discharge and shivering.

\section{RNA purification and RT-PCR for $G$ protein gene}

Total RNA from the defibrinated blood samples and the samples supplied from the mosquito pools was extracted from the samples using RNeaseyKits (Qiagen, 19300 Germantown Road Germantown, MD20874). cDNA Synthesis Kit (Thermo Fisher Scientific, USA) was used according to the manufacturer's instructions and cDNA synthesis from RNA was realized. After that, identification and $G$ gene-based characterization of BEFV was realized with oligonucleotide (Table 2). PCR procedure was conducted according to the protocol described by AzizBoaron et al. 2012 Amplification products were analyzed with $1 \%$ agarose gel electrophoresis and viewed under UV light (Fig 2).

\section{Gene sequence and phylogenetic analysis}

PCR products that were purified using High Pure PCR Products Purification kit were automatically made in an analyzer (CEQ 8000; Beckman Coulter, Brea, CA, USA) using the Kit (Roche Applied Sciences, Germany). Row arrangement and multiple alignments were made with the Bioedit software pack, version 7.0.9.0. (Hall, 1999). Preloading analysis and phylogenetic analysis were made using Kimura 2 parameter correction. MEGA (Molecular Evolutionary Genetics Analysis) software pack, version 5.0 (Tamura et al. 2011).

\section{RESULTS AND DISCUSSION}

As a result of tests, 21 out of 46 blood samples (Table 1) tested were positive for BEFV with RT-PCR with amplicons in expected size (809-bp long). When the mosquito pools (Table 1) were tested with RT-PCR, all of them were negative. The rates of positivity of the blood samples taken from the facilities sampled in Sur, Çınar and Dicle were $63.30 \%(16 /$ $26), 22.22 \%$ (2/9) and $27.27 \%$ (3/11), respectively. Among the positive amplicons, one from each of the facilities in Dicle and Sur and two in Çınar were subject to partial sequence analysis. The sequences have the accesses numbers of MW478602 Çınar-Diyarbakır 2020, MW512836 Dicle-Diyarbakır 2020, MW512834 Sur-Diyarbakır 2020, MW512835 Sukrulu-Diyarbakır 2020 in GenBank. The BEFV $G$ protein gene partial sequences obtained in this study were compared to the other BEFV sequences obtained from the GenBank database (Fig 1). As a result of this comparison, it was found that the sequences obtained from the epidemic in Turkey in 2020 (MW478602 Çınar-Diyarbakır 2020, MW512836 Dicle-Diyarbakır 2020, MW512835 SurDiyarbakır 2020, MW 680306.1_BEFTR63_TR_2020) were in the same group (Turkey-2). In the phylogenetic comparison, it was found that the sequences obtained from the BEFV 2020 epidemic and placed in the Turkey-2 group were identical to the MN839987.1_IND_2018 variant (Table 3).

The epidemic BEFV infection, after having been experienced in Turkey in 1985, 2008 and 2012, broke out in Turkey again after eight years, in August 2020. Molecular studies have been commonly used in recent years in identifying the variants of the virus that caused these epidemics. Identifying the virus strain in every epidemic by conducting sequence analyses for these viruses that cause these endemics is important for filiation and selecting the suitable vaccine to fight against the disease. This study intended to identify the variant of the virus that caused an

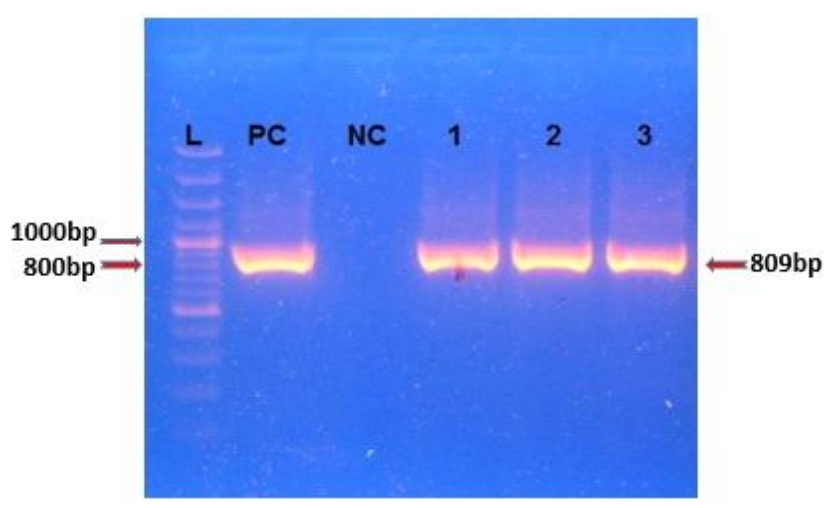

Fig 1: An 1\% agarose gel electrophoresis of BEF samples of three 809 bp nested PCR first round aplicon isolates representing the groups identified by the phylogenetic analysis.

Table 1: Sampling centers, number of facilities, breeds of animals in the facility, number of samples in the BEFV2020 epidemic.

\begin{tabular}{lcccc}
\hline & $\begin{array}{c}\text { Latitude } \\
\text {-Longitude }\end{array}$ & $\begin{array}{c}\text { Number of facilities, } \\
\text { Breed }\end{array}$ & $\begin{array}{c}\text { Number of mosquito } \\
\text { pools }\end{array}$ & $\begin{array}{c}\text { Number of defibrinated } \\
\text { blood samples }\end{array}$ \\
\hline Sur & $37.91055^{\circ} \mathrm{K}$ & 1, Holstein & 4 & 26 \\
\multirow{3}{*}{ Çinar } & $40.23595^{\circ} \mathrm{D}$ & & & 9 \\
& $37.7241^{\circ} \mathrm{K}$ & 1 , Holstein & 4 & 11 \\
Dicle & $40.4135^{\circ} \mathrm{D}$ & & 4 & \\
& $38.3733^{\circ} \mathrm{K}$ & 1, Holstein & & 4 \\
\hline
\end{tabular}


epidemic in Turkey in 2020. The phylogenetic analysis based on the $G$ gene partial analyses of the BEFVs demonstrated that it was caused by a different variant from the viruses that caused epidemics in previous years. Although the virus variant that caused an epidemic in 2008 and 2012 had genetic similarities with the viruses in the Turkey-1 group, the virus that caused an epidemic in 2020 had genetic similarities with the ones in the Turkey-2 group. Even though the Turkey-1 group had genetic similarities with the strains from the Middle East, Turkey-2 group viruses demonstrate similarities with the Indian virus strain with $99.4 \%$ homology, although the 2020 endemic viruses are 100\% homolog among themselves. In this case, the endemic was caused by a new variant virus strain as it was not $100 \%$ identical to the Indian virus strain (Fig 1). However, different variants were identified in the phylogenetic studies conducted during the BEFV virus epidemics in India in 2018-19, demonstrated that monsoon winds were influential in spreading the virus (Pyasi, 2020). The phylogenetic tree revealed that BEF viruses from the 2008 and 2012 epidemics in Turkey were placed in the same cluster as that of the Israel isolates (Turkey-1), as shown in Fig 1 while new varyant the 2020 epidemic BEFVs were placed in a different cluster with the
India in 2018-19 Indian strains (Turkey-2), as shown in Fig 1.

Although BEFVis serologically monotypic (Walker, 2005), in comparative analyses of the amino acid sequences of the $\mathrm{G}$ gene, since the polyclonal antibodies created by each genogroup depending on antigenic change are different, it was found that possible cross-protection varied between genogroups (Kato et al., 2009). New endemics break out in specific periods due to genotypically different virus variants depending on the fact that protection drops from time to time due to the difference in polyclonal protection caused by different genotypes (Kato et al., 2009). The BEFV epidemic broke out again in August 2020, 8 years later, after being observed in 1985, 2008 and 2012 in Turkey. The cause of these epidemics, BEFV G protein gene nucleotide identity and deviation percentages are shown in Table 1. Although the nucleotide similarity was $100 \%$ among the sequences obtained from the epidemic in 2020 , it is $96.2 \%$ in those from the epidemic in 2012 and $96.4 \%$ in those from the endemic in 2008 . The nucleotide similarity of the sequences from the 2020 epidemic in the Turkey-2 group was $99.4 \%$ at the highest with the MN839987.1_IND_2018 variant (Table 3). The fact that

Table 2: Oligonucleotide, nucleotide intervals and references used in RT-PCR test.

\begin{tabular}{lcc}
\hline Primers: & Nucleotides & Reference \\
\hline BEF346F: 5'-TATTACCCTCCTGCCGGATGCTTT-3' & $246-369$ & 10 \\
BEF1155R: 5'-AGGTCTGTATTCGCACCAAGCTCT-3' & $1132-1155$ & 10 \\
\hline
\end{tabular}

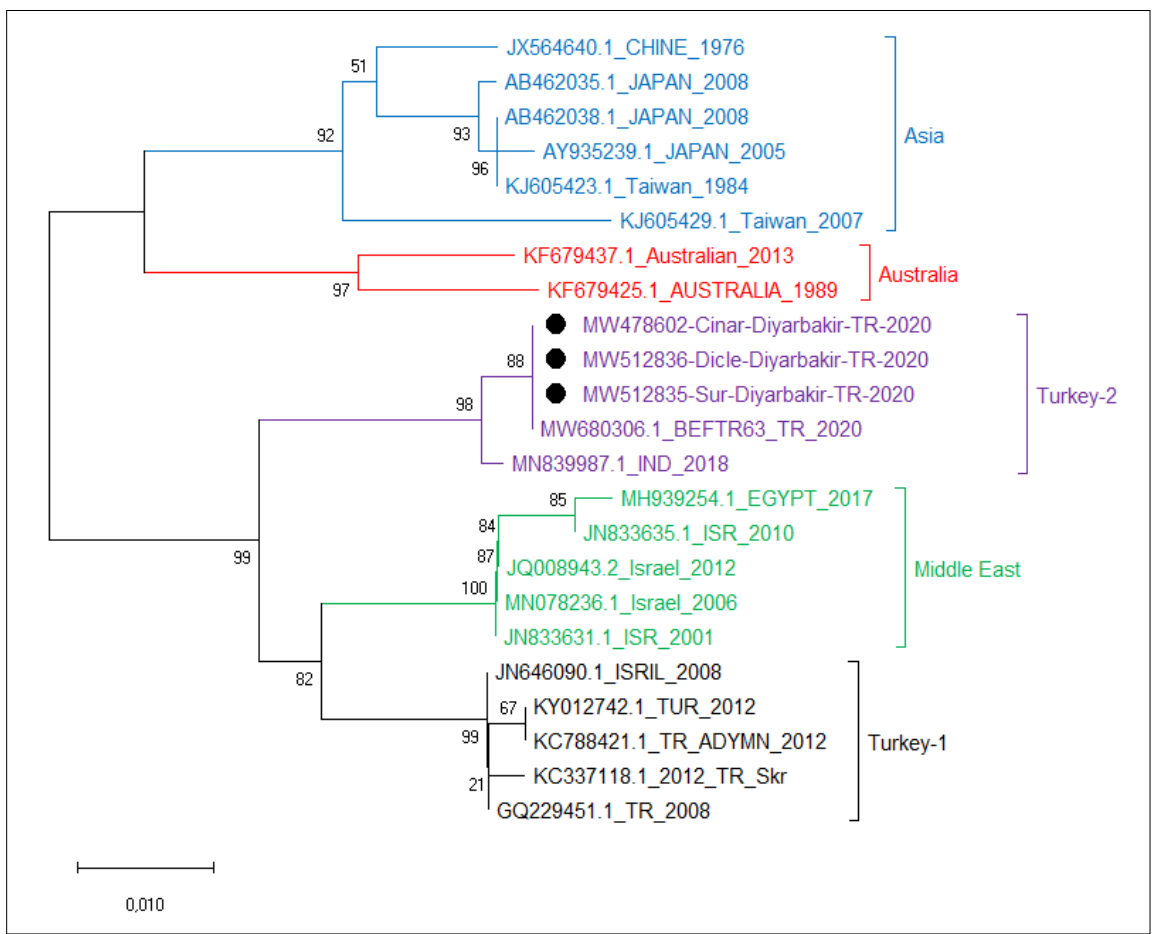

Fig 2: The phylogenetic tree based on the nucleotide sequences of the $G$ gene and access numbers of the $G$ gene regional sequences (obtained from the GenBank database) of Turkish BEFV strains and BEFV strains from various countries are shown in the phylogenetic tree used in this study. 


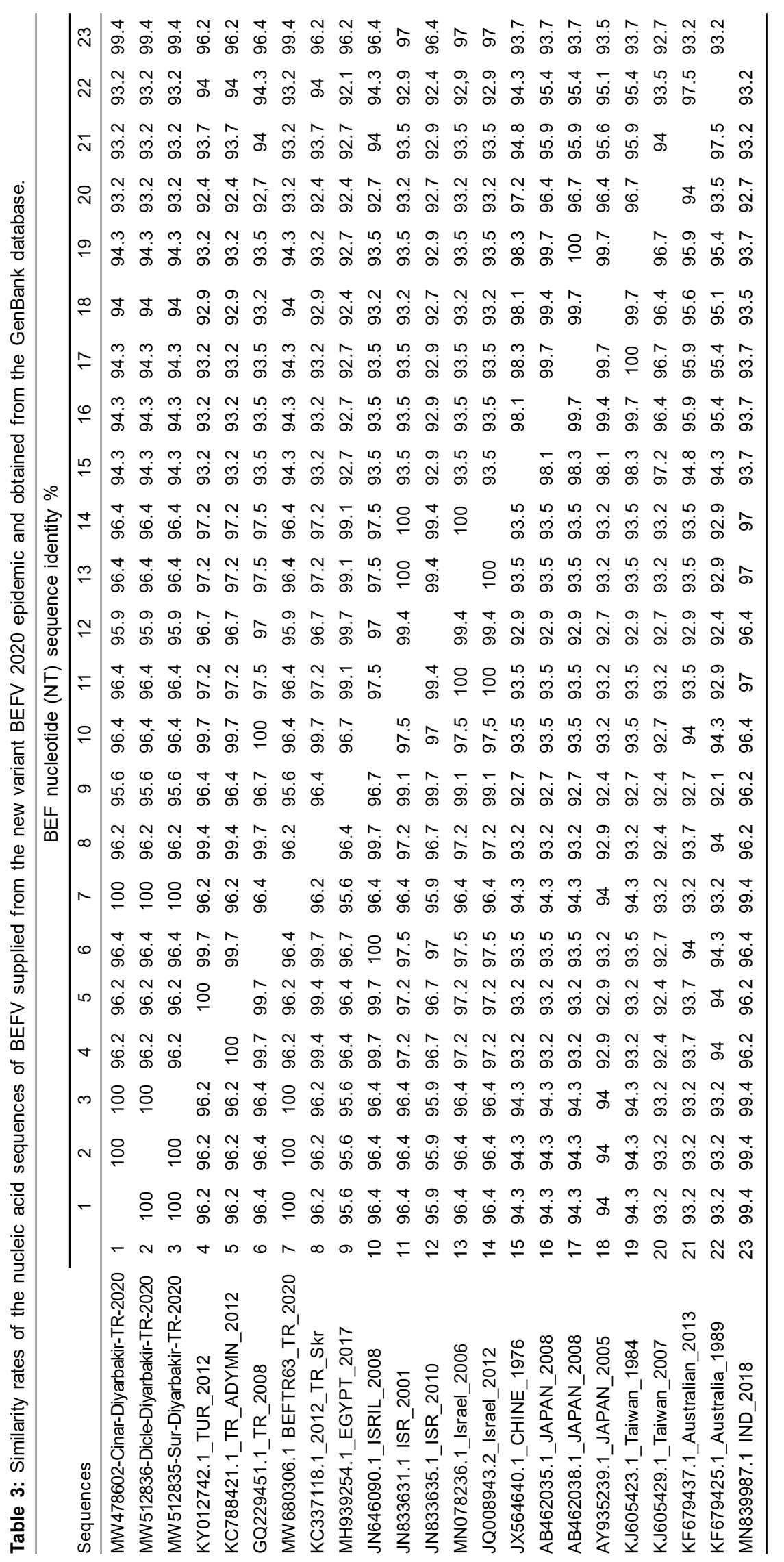


viruses similar to the 2012 Turkey NEFV epidemic also caused an epidemic in India around those times demonstrated that monsoon winds impacted the intercontinental spread of the virus (Pyasi et al., 2020).

BEFV's vector population was unclear and the infection's global geodynamics was not completely understood. Epidemiologic studies in BEFV epidemics identified a close relationship between meteorological data and viral epidemics. This data showed BEFV epidemics spread between continents through hot wind flows that carried infected vectors (Pyasi et al., 2020; Shirakawa et al., 1994; Tuffereau et al., 1989; Zheng and Qiu, 2012). From the molecular epidemiologic perspective, the fact that the virus variant identified in the 2020 endemic is $99.4 \%$ similar to the Indian variant gives the conclusion that the virus might have spread through the virus carried by vectors through hot winds. However, in this study, the BEFV virus was not detected in the vector mosquito pools placed at places where the disease was observed. There is no scientific report that concludes the virus was identified on vectors in Turkey (Karayel et al., 2021). In molecular epidemiologic studies (Pyasi et al., 2020; Alkan et al., 2017; Karayel et al., 2021), a close relationship was detected between meteorological data and viral epidemics. Furthermore, new variants will emerge in time depending on mutations in the virus genome. For this reason, viral infections among similar arboviral infections such as the bluetongue virus, Schammellenberg virus, Akabane virus, West Nile virus and BEFV virus infection epidemics can occur in Turkey and Europe in the future (Dik et al., 2014).

It was determined that the BEFV Turkey-2 variant caused more severe clinical symptoms and higher morbidity and mortality rates compared to previous endemics based on the information provided by farmers and veterinaries. The reason for this is that in molecular phylogenetic analyses, BEFV was close to the Indian variant but a new variant differently from the viruses that caused epidemics in Turkey in the past. Therefore, changes in the virulence of BEFV should be monitored. The impact of a viral infection on the body is related to the host immunity, susceptibility of the sick individual and the virus's characteristics. BEFV is an RNA virus with a high mutation rate that does not have error correction mechanisms after replication (Dik et al., 2014). Considering the studies made on the virulence of Rhabdoviridae the virus family that BEFV is grouped in (Tuffereau et al., 1989; Faber et al., 2015), it was reported that the variation in the amino acids of the viral glycoprotein altered the impacts of the virus on pathogenicity.

\section{CONCLUSION}

The control of BEFV infection depends on protection from vector infestation, which is effective in infection and vaccination. Within the scope of the natural BEFV 2020 endemic in Turkey, we do not have a vaccination program or any data on immunization status. It is necessary to conduct further epidemiologic studies and research on vector identification and procedures on supplying and producing efficient vaccine strains for effective preventive and control measures against this infection.

\section{REFERENCES}

Alkan, F., Albayrak, H., Timurkan, M. O., Ozan, E. and Coskun, N. (2017). Assessment of the molecular epidemiology of bovine ephemeral fever in Turkey. Veterinarski Archive. 87: 665-675.

Aziz-Boaron, O., Klausner, Z., Hasoksuz, M., Shenkar, J., Gafni, O., Gelman, B. and Klement, E. (2012). Circulation of bovine ephemeral fever in the Middle East-strong evidence for transmission by winds and animal transport. Veterinary Microbiology. 158: 300-307.

Dik, B., Muz, D., Muz, M.N. and Uslu, U. (2014). The geographical distribution and first molecular analysis of Culicoides Latreille (Diptera: Ceratopogonidae) species in the Southern and South-eastern Turkey during the 2012 outbreak of bovine ephemeral fever. Parasitology Research. 113: 4225-4232.

Faber, M., Faber, M. L., Papaneri, A., Bette, M., Weihe, E., Dietzschold, B. and Schnell, M.J. (2005). A single amino acid change in rabies virus glycoprotein increases virus spread and enhances virus pathogenicity. Journal of Virology. 79 : 14141-14148.

Girgin, H., Yonguç, A.D., Akçora, A. and Aksak, E. (1986). The first bovine ephemeral fever endemic in Turkey. Etlik Veterinary Microbiology Journal. 5: 5-14.

Hall, T.A. (1999). BioEdit: A user-friendly biological sequence alignment and analysis program for Windows 95/98/NT. In Nucleic Acids Symposium. 41: 95-98.

Karayel-Hacioglu, I., Yelken, S.D., Vezir, Y., Unal, N. and Alkan, F. (2021). Isolation and genetic characterization of bovine ephemeral fever virus from epidemic-2020 in Turkey. Tropical Animal Health and Production. 53: 1-7.

Kato, T., Aizawa, M., Takayoshi, K., Kokuba, T., Yanase, T., Shirafuji, H. and Yamakawa, M. (2009). Phylogenetic relationships of the $\mathrm{G}$ gene sequence of bovine ephemeral fever virus isolated in Japan, Taiwan and Australia. Veterinary Microbiology. 137: 217-223.

Lee, F. (2019). Bovine ephemeral fever in Asia: recent status and research gaps. Viruses. 11:412.

Oğuzoğlu, T.Ç., Ertürk, A., Çizmeci, Ş.G., Koç, B.T. and Akça, Y. (2015). A report on bovine ephemeral fever virus in Turkey: Antigenic variations of different strains of EFV in the 1985 and 2012 outbreaks using partial glycoprotein gene sequences. Transboundary and Emerging Diseases. 62: 66-70.

Pyasi, S., Sahu, B.P., Sahoo, P., Dubey, P.K., Sahoo, N., Byrareddy, S.N. and Nayak, D. (2020). Identification and phylogenetic characterization of bovine ephemeral fever virus (BEFV) of Middle Eastern lineage associated with 2018-2019 outbreaks in India. Transboundary and Emerging Diseases. 67: 2226-2232

Radostits, O.M., Gay, C.C., Hinchcliff, K.W. and Constable, P.D. (Eds.). (2006). Veterinary Medicine E-Book: A Textbook of the Diseases of Cattle, Horses, Sheep, Pigs and Goats. Elsevier Health Sciences. 
Shirakawa, H., Ishibashi, K. and Ogawa, T. (1994). A comparison of the epidemiology of bovine ephemeral fever in South Korea and south western Japan. Australian Veterinary Journal. 71: 50-52.

Tamura, K., Peterson, D., Peterson, N., Stecher, G., Nei, M. and Kumar, S. (2011). MEGA5: Molecular evolutionary genetics analysis using maximum likelihood, evolutionary distance and maximum parsimony methods. Molecular Biology and Evolution. 28: 2731-2739.

Thabet, N.S., Ghazy, E.W., Nayel, M.A. and Abo-Elkhair, M. (2011). Molecular and biochemical studies on bovine ephemeral fever. Research Opinions in Animal and Veterinary Sciences. 1: 69-275.

Tonbak, S., Berber, E., Yoruk, M.D., Azkur, A.K., Pestil, Z. and Bulut, H. (2013). A large-scale outbreak of bovine ephemeral fever in Turkey, 2012. Journal of Veterinary Medical Science. 75: 1511-1514.
Tuffereau, C., Leblois, H., Benejean, J., Coulon, P., Lafay, F. and Flamand, A. (1989). Arginine or lysine in position 333 of ERA and CVS glycoprotein is necessary for rabies virulence in adult mice. Virology. 172: 206-212.

Walker, P.J., Byrne, K.A., Cybinski, D.H., Doolan, D.L. and Wang, Y. (1991). Proteins of bovine ephemeral fever virus. Journal of General Virology. 72: 67-74.

Walker, P.J. (2005). Bovine ephemeral fever in Australia and the world. The World of Rhabdoviruses. 292: 57-80.

Walker, P.J. and Klement, E. (2015). Epidemiology and control of bovine ephemeral fever. Veterinary Research. 46: 1-19.

Zaher, K.S. and Ahmed, W.M. (2011). Investigations on bovine ephemeral fever virus in Egyptian cows and buffaloes with emphasis on isolation and identification of a field strain. Global Veterinaria. 6: 447-452.

Zheng, F. and Qiu, C. (2012). Phylogenetic relationships of the glycoprotein gene of bovine ephemeral fever virus isolated from mainland China, Taiwan, Japan, Turkey, Israel and Australia. Virology Journal. 9: 1-8. 